\title{
Comparative safety of artemether-lumefantrine and other artemisinin-based combinations in children: a systematic review
}

\author{
Oluwaseun Egunsola ${ }^{1 *}$ and Kazeem A Oshikoya ${ }^{2}$
}

\begin{abstract}
Background: The purpose of the study was to compare the safety of artemether-lumefantrine (AL) with other artemisinin-based combinations in children.

Methods: A search of EMBASE (from 1974 to April 2013), MEDLINE (from 1946 to April 2013) and the Cochrane library of registered controlled trials for randomized controlled trials (RCTs) which compared AL with other artemisinin-based combinations was done. Only studies involving children $\leq 17$ years old in which safety of AL was an outcome measure were included.

Results: Four thousand, seven hundred and twenty six adverse events (AEs) were recorded in 6,000 patients receiving AL. Common AEs $(\geq 1 / 100$ and $<1 / 10)$ included: coryza, vomiting, anaemia, diarrhoea, vomiting and abdominal pain; while cough was the only very commonly reported $A E(\geq 1 / 10)$. AL-treated children have a higher risk of body weakness (64.9\%) than those on artesunate-mefloquine (58.2\%) ( $p=0.004$, RR: 1.12 95\% Cl: 1.04-1.21). The risk of vomiting was significantly lower in patients on $\mathrm{AL}(8.8 \%)$ than artesunate-amodiaquine $(10.6 \%)(p=0.002$, RR: $0.76,95 \%$ Cl: 0.63-0.90). Similarly, children on AL had a lower risk of vomiting (1.2\%) than chlorproguanil-dapsoneartesunate (ACD) treated children (5.2\%) ( $p=0.002$, RR: $0.63,95 \% \mathrm{Cl}: 0.47-0.85)$. The risk of serious adverse events was significantly lower for AL (1.3\%) than ACD (5.2\%) ( $p=0.002$, RR: $0.45,95 \%$ Cl: $0.27-0.74)$.

Conclusion: Artemether-lumefantrine combination is as safe as ASAQ and DP for use in children. Common adverse events are cough and gastrointestinal symptoms. More studies comparing AL with artesunate-mefloquine and artesunate-azithromycin are needed to determine the comparative safety of these drugs.
\end{abstract}

Keywords: Artemether-lumefantrine, Adverse event, Paediatrics, Children, Safety

\section{Background}

Malaria, caused by Plasmodium falciparum, is an important public health problem in Africa. It accounts for an estimated 660,000 deaths in 2010, mostly among African children [1]. Due to the increasing resistance of malaria parasite to older anti-malarial drugs, such as chloroquine and sulphadoxine-pyrimethamine, artemisinin-based combination therapy (ACT) has been recommended by the World Health Organization (WHO) [2]. This approach involves the combination of artemisinin, or one of its derivatives, with other anti-malarials, such as amodiaquine,

\footnotetext{
* Correspondence: mzxoe@nottingham.ac.uk

'Academic Division of Child Health, University of Nottingham, Derbyshire Children's Hospital, Derby DE22 3DT, UK

Full list of author information is available at the end of the article
}

lumefantrine or sulphadoxine-pyrimethamine. Several studies have demonstrated the efficacy of ACT for malaria treatment [3]. A combination therapy explores the synergistic or additive effect of two or more drugs with different mechanisms of action to improve the therapeutic efficacy, increase the therapeutic drug life and delay the development of resistance to each of the component drugs in the combination [4].

Artemether-lumefantrine (AL) is one of the most commonly used combinations in sub-Saharan Africa. It is the first-line treatment for uncomplicated malaria in several countries. It is available in oral form as a fixed dose combination (20 mg artemether and $120 \mathrm{mg}$ lumefantrine) and given as a six dose regimen for the treatment of uncomplicated malaria. Artemether has a short half-

\section{Biomed Central}

(c) 2013 Egunsola and Oshikoya; licensee BioMed Central Ltd. This is an open access article distributed under the terms of the Creative Commons Attribution License (http://creativecommons.org/licenses/by/2.0), which permits unrestricted use, distribution, and reproduction in any medium, provided the original work is properly cited. 
life of 2-3 hours, while lumefantrine has a half-life of about 5 days [4-6]. Artemether rapidly and extensively reduces parasite biomass, while lumefantrine clears the residual parasites from the body [7].

Although AL is widely prescribed, several other combinations are increasingly being explored and used but data are lacking on their safety. Most of the previous studies have compared the efficacies of AL and other artemisinin-based combinations, but little or no attention has been given to their safety. AL has been shown to be relatively safe when compared with other antimalarials such as quinine, sulphadoxine-pyrimethamine and chloroquine [8]. Adverse effects, such as headache, dizziness, abdominal pain anorexia, anaemia, arthralgia, myalgia, diarrhoea, vomiting, nausea, weakness and rash, have been documented $[9,10]$. Given the wide range of ACT available for malaria treatment and their potential adverse effects, it is imperative to compare their safety profiles. This systematic was, therefore, performed to compare the safety profiles of AL with other ACT in children.

\section{Methods}

Search strategy

Embase (from January 1974 to April 2013), Medline (from January 1946 to April 2013) and the Cochrane library of registered controlled trials for randomized controlled trials (RCTs) were searched for RCTs comparing AL with other artemisinin-based combinations. Search terms such as artemisinin or artemether or artesunate or dihydroartemisinin were combined with lumefantrine or amodiaquine or sulphadoxine-pyrimethamine or mefloquine or chloproguanil or dapsone or piperaquine or azithromycin. Only studies involving children $\leq 17$ years old in which safety of AL was an outcome measure were included. There was no restriction on the language of publication.

\section{Data extraction}

Two reviewers extracted data from the included studies onto data extraction form.

Data extracted from each study included: the comparator drug, the number of participants in each arm of the study, year of the study, duration of follow-up, age of the participants, dose of drugs administered, the number of deaths recorded, the number of participants who withdrew from the study, and the adverse event (AE) data for both $\mathrm{AL}$ and the comparator drugs. All data were compared and agreed to by both reviewers.

\section{Data quality assessment}

To minimize the risk of bias, the quality of included randomized controlled trials was assessed using the Cochrane collaboration's tool for assessing risk of bias in randomized trials [11]; quality of reported safety studies was also assessed using the modified CONSORT checklist for reporting of harmful effects [12]. Articles with modified CONSORT score of $\geq 6$ out of 9 criteria were considered to have provided good quality safety reporting. All RCTs were included for meta-analyses. Highly biased and poor quality studies were subsequently excluded in sensitivity analysis. Two reviewers independently scored and agreed on articles included. Kappa statistic was used to determine the level of agreements on the quality assessment between the two reviewers $(\mathrm{k}$ $=0.92)$ [13].

\section{Data collection and statistical analysis}

The relevant data were extracted onto an excel spread sheet. All studies were grouped based on the comparator drug and AEs in each pool were aggregated for metaanalysis. The adverse event profile of AL was used as the reference against which other artemisinin-based combinations were compared. Meta-analysis was done using Revman version 5. Relative risk was calculated for all AEs reported in more than one study. A relative risk $(\mathrm{RR})>1$ indicates a higher risk of AE in AL relative to the comparator. The pooled RR was calculated using the fixed effect model for homogenous data $\left(\mathrm{I}^{2} \leq 50 \%\right.$ or $\left.\mathrm{Chi}^{2} \mathrm{p} \geq 0.05\right)$ and random effect model for heterogeneous data $\left(\mathrm{I}^{2}>50 \%\right.$ or $\left.\mathrm{Chi}^{2} \mathrm{p}<0.05\right)$ as suggested by DerSimonian and Laird [14].

\section{Results}

Safety information was extracted from 27 RCTs (Figure 1), which met our inclusion criteria [15-41]. After risk of bias assessment, 7 studies were of high risk [23-25,34-37]. The age of the patients ranged between six weeks and 18 years (Table 1). In all studies, a six-dose regimen of AL (20 mg artemether and $120 \mathrm{mg}$ lumefantrine) was administered over three days. The total number of children administered ACT was 15,119 . Four thousand, seven hundred and twenty six AEs were recorded in 6,000 patients receiving AL. All but one of the RCTs, were conducted in Africa (Nigeria, Ghana, Benin, Uganda, Kenya, Tanzania, Ivory Coast, Burkina Faso, Senegal and Gabon). The only non-African country was Paupa New Guinea. Common AEs $(\geq 1 / 100$ and $<1 / 10)$ among patients receiving AL included: coryza, vomiting, anaemia, diarrhoea, vomiting and abdominal pain; while cough was the only very commonly reported $\mathrm{AE}(\geq 1 / 10)$ (Table 2). The respiratory and gastrointestinal tracts were the most commonly affected systems constituting $35 \%$ and $33 \%$ respectively, of all the reported AEs in AL treated children. Other artemisinin based combinations compared with AL were: artesunateamodiaquine (ASAQ), dihydroartemisinin-piperaquine (DP), chlorproguanil-dapsone-artesunate (ACD), artesunatemefloquine (AM) and artesunate-azithromycin (AAZ). 


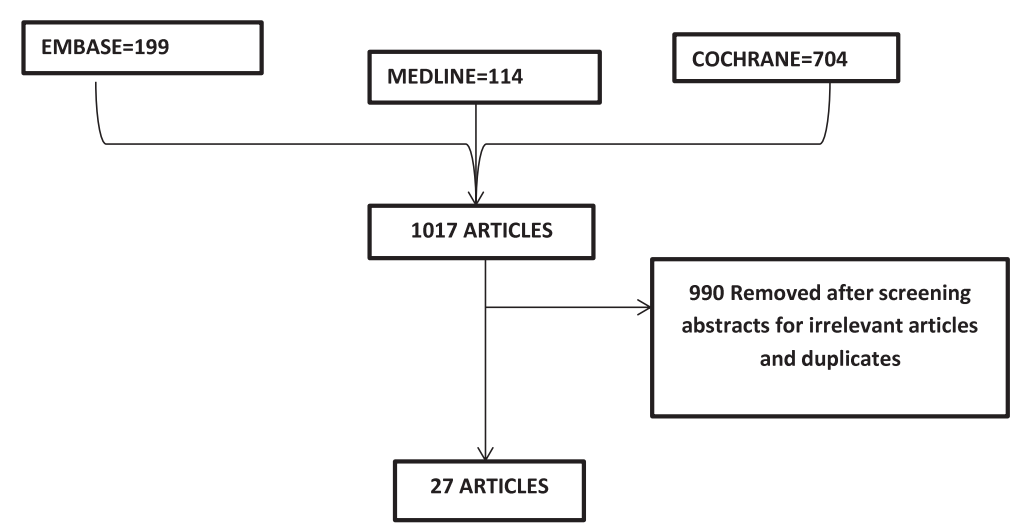

Figure 1 Flow chart for studies included in the systematic review.

\section{$A L$ and DP}

Eleven studies involving 5958 children compared AL with DP [15-25]. There were three cases of death in each of the drug groups; none was related to the drugs. The risk of serious adverse events (SAEs) was lower with AL (0.5\%) than DP (1.2\%), although this difference was not statistically significant $(\mathrm{p}=0.09, \mathrm{RR} \quad 0.62$ 95\%CI 0.36 1.07). In one of the studies, two unnamed SAEs in AL arm and four in DP group were considered to have causal relationship with the drugs [20]. In another study, one patient receiving AL developed severe anaemia, which was considered to be possibly associated with the drug [22]. In Table 3, the children receiving AL had a minimally higher risk of abdominal pain (10.9\%) than those receiving DP (10.4\%) ( $p=0.09$, RR 1.31, 95\% CI $0.99-1.73)$. After a study with a high risk of bias [24] was excluded in a sensitivity analysis, the risk of abdominal pain was statistically significant $(\mathrm{p}=0.04)$. Table 3 shows that the risks of other common adverse events such as pruritus, diarrhoea, cough, vomiting and weakness of the body were not significantly different between the two drug groups $(\mathrm{p}>0.05)$.

\section{$A L$ and $A S A Q$}

Thirteen studies involving 6018 children comparing AL with ASAQ were included and analysed [20,26-37]. The risk of SAEs was not significantly different for both treatment groups ( $p=0.07$ RR: $0.54,95 \%$ CI: $0.27-1.05$ ).
The percentage risks of SAEs in the AL and ASAQ groups were $0.8 \%$ and $1.5 \%$ respectively. Most of the reported SAEs were judged to be unlikely related to the medications studied. However in one study [20], four unnamed SAEs in patients receiving ASAQ and two in those receiving $\mathrm{AL}$ were considered to be drug related. There were only three documented cases of mortality, two in the AL group and one in the ASAQ group. None of the deaths was treatment related. Table 3 shows that the risk of vomiting was significantly lower in patients on AL (8.8\%) than ASAQ (10.6\%) ( $\mathrm{p}=0.002$, RR: 0.80 , 95\% CI: $0.66-$ 0.97). After excluding one poor quality RCT [34] in a sensitivity analysis, the risk of vomiting remained statistically significant $(p=0.002)$. The risk of other AEs, such as weakness, pruritus, anaemia, diarrhoea, abdominal pain, anorexia and cough, was not statistically significant $(\mathrm{p}>0.05)$ with or without biased RCTs.

\section{$A L$ and $A C D$}

Three studies comparing AL with ACD involving 3366 children were included in this review [20,26,38]. Two of these studies compared more than one artemisininbased combination. All included RCTs were rated as low risk. The overall risk of SAE was significantly lower for AL (1.3\%) than ACD (5.2\%) ( $\mathrm{p}=0.002$, RR: 0.45, 95\% CI: $0.27-0.74)$. Forty-six (73\%) and three (20\%) of the SAEs in the ACD and AL groups, respectively, were due to oxidative haemolysis. Majority of the haemolytic AEs in

Table 1 Characteristics of treatment groups

\begin{tabular}{|c|c|c|c|c|c|}
\hline Drugs & $A L$ and $D P$ & $A L$ and $A C D$ & $A L$ and $A S A Q$ & AL and $A M$ & $A L$ and $A A Z$ \\
\hline Age range(months) & $6-168$ & $6-180$ & $1.5-120$ & $6-216$ & $6-59$ \\
\hline Median (IQR) duration of follow-up (days) & $35(22.8-51.8)$ & $35(12.3-42)$ & $28(21-42)$ & 28 & 42 \\
\hline Number of studies & 11 & 3 & 13 & 2 & 1 \\
\hline Number of patients in AL arm & 3343 & 1861 & 3054 & 239 & 132 \\
\hline Number in comparator arm & 4284 & 1505 & 2964 & 237 & 129 \\
\hline
\end{tabular}


Table 2 Organ-system classification and risk of adverse events in AL treated children

\begin{tabular}{|c|c|c|c|}
\hline System organ class & Adverse event & Number of adverse events & Risk (per 1000 patients) \\
\hline \multirow[t]{5}{*}{ Gastrointestinal disorders } & Abdominal pain & 187 & 31.2 \\
\hline & Anorexia & 442 & 73.7 \\
\hline & Diarrhoea & 371 & 61.8 \\
\hline & Nausea/vomiting & 471 & 78.5 \\
\hline & Others & 109 & 18.2 \\
\hline \multirow[t]{8}{*}{ General disorders } & Weakness & 372 & 62 \\
\hline & Pyrexia & 372 & 62 \\
\hline & Mouth ulcer & 13 & 2.2 \\
\hline & Salivation & 7 & 1.2 \\
\hline & Unable to suck & 5 & 0.8 \\
\hline & Body pain & 10 & 1.7 \\
\hline & Hypersensitivity reaction & 3 & 0.5 \\
\hline & Puffy face & 1 & 0.2 \\
\hline \multirow[t]{4}{*}{ Respiratory disorders } & Cough & 1152 & 192 \\
\hline & Coryza & 449 & 74.8 \\
\hline & Dyspnoea & 4 & 0.7 \\
\hline & Others & 55 & 9.2 \\
\hline \multirow[t]{5}{*}{ Central Nervous system disorders } & Headache & 228 & 38 \\
\hline & Dizziness & 18 & 3 \\
\hline & Insomnia & 23 & 3.8 \\
\hline & Convulsion & 3 & 0.5 \\
\hline & Nystagmus & 1 & 0.2 \\
\hline \multirow[t]{4}{*}{ Skin and appendages disorders } & Rash & 55 & 9.2 \\
\hline & Pruritus & 90 & 15 \\
\hline & Urticaria & 2 & 0.3 \\
\hline & Others & 35 & 5.8 \\
\hline \multirow[t]{4}{*}{ Haematological disorders } & Anaemia & 157 & 26.2 \\
\hline & Haemolysis & 3 & 0.5 \\
\hline & Thrombocytopaenia & 9 & 1.5 \\
\hline & Neutropenia & 42 & 7 \\
\hline \multirow[t]{3}{*}{ Liver and biliary system disorders } & Jaundice & 3 & 0.5 \\
\hline & Elevated ALT & 23 & 3.8 \\
\hline & Hepatomegaly & 4 & 0.7 \\
\hline Musculo-skeletal system disorders & Joint pain & 1 & 0.2 \\
\hline Cardiovascular disorders & Palpitation & 6 & 1 \\
\hline
\end{tabular}

the ACD group (56.5\%) occurred in G6PD deficient children. All the three cases of haemolysis in the AL group were in G6PD normal children. There were three and four cases of deaths, respectively, for $\mathrm{AL}$ and $\mathrm{ACD}$; none was considered treatment related. In Table 3, the risk of vomiting was significantly lower for $\mathrm{AL}(1.2 \%)$ than ACD (5.2\%) ( $p=0.002$, RR: 0.63, 95\% CI: 0.47-0.85). No other adverse event showed a statistically significant difference between both drugs.

\section{AL and AM}

Two studies involving 476 children compared AL with AM $[39,40]$. None of the studies reported death or SAEs for both drugs. In Table 3, pooled analyses of both RCTs showed a statistically significantly higher risk of weakness for AL treated children (64.6\%) than AM (58.2\%) ( $p=0.004$, RR: 1.12 95\% CI: 1.04-1.21). Vomiting and abdominal pain, which were the other two AEs reported in both studies, were not significantly different in both treatment groups. 
Table 3 Relative risk of AEs between AL and other artemisinin-based combinations

\begin{tabular}{|c|c|c|c|c|c|}
\hline \multicolumn{6}{|c|}{ Relative risk of $A E s$ between $A L$ and DP } \\
\hline Adverse event & Risk AL (\%) & Risk comparator (\%) & Relative risk $(95 \% \mathrm{Cl})$ & $P$ value (* significant) & References \\
\hline Vomiting & 10.3 & 9.7 & $0.99[0.86-1.13]$ & 0.85 & $15-24$ \\
\hline ‡Anaemia & 3.7 & 10.1 & $0.45[0.20-1.02]$ & 0.05 & 18,20 \\
\hline Abdominal pain & 10.9 & 10.4 & $1.31[0.99-1.73]$ & 0.06 & $17,19,21,24$ \\
\hline Diarrhoea & 13.3 & 12.6 & $1.03[0.89-1.20]$ & 0.65 & $15-18,20-24$ \\
\hline Pruritus & 5.8 & 4.5 & $1.28[0.81-2.02]$ & 0.30 & $17,19,21,24$ \\
\hline Weakness & 16.5 & 13.3 & $1.14[0.94-1.39]$ & 0.19 & $15,17,19,21,24$ \\
\hline Cough & 39.8 & 39.2 & $0.99[0.92-1.05]$ & 0.65 & $15,17-19,20-22,24$ \\
\hline Anorexia & 12.3 & 11.0 & $1.07[0.93-1.24]$ & 0.38 & $15,17,19-22$ \\
\hline SAE & 0.5 & 1.2 & $0.62[0.36-1.07]$ & 0.09 & $15-22$ \\
\hline \multicolumn{6}{|c|}{ Relative risk of $A E s$ between $A L$ and $A S A Q$} \\
\hline Abdominal pain & 14.5 & 14.3 & $0.81[0.46-1.40]$ & 0.45 & $26,28,29,31-34$ \\
\hline Pruritus & 8.4 & 9.5 & $0.78[0.54-1.11]$ & 0.17 & $26,28,31,34$ \\
\hline Anorexia & 14.3 & 17.6 & $0.88[0.76-1.03]$ & 0.11 & $20,26,29,31$ \\
\hline ‡Anaemia & 8.9 & 19.1 & $0.61[0.19-1.90$ & 0.39 & $20,30,31,33$ \\
\hline Headache & 13.5 & 7.9 & $1.29[0.89-1.87]$ & 0.17 & $29,32,34$ \\
\hline Vomiting & 8.8 & 10.6 & $0.80[0.66-0.97]$ & *0.02 & $20,26,28-31,33,34$ \\
\hline Weakness & 12.8 & 13.4 & $0.84[0.63-1.13]$ & 0.25 & $28,29,31,34$ \\
\hline Diarrhoea & 12.0 & 10.4 & $1.09[0.89-1.32]$ & 0.41 & $20,27,32,34$ \\
\hline Cough & 31.4 & 31.2 & $1.01[0.91-1.12]$ & 0.84 & $20,27,30,32,33$ \\
\hline SAE & 0.8 & 1.5 & $0.54[0.27-1.05]$ & 0.07 & $20,30-32$ \\
\hline \multicolumn{6}{|c|}{ Relative risk of $A E s$ between $A L$ and $A C D$} \\
\hline ‡Anaemia & 2.8 & 7.2 & $0.35[0.09-1.43]$ & 0.15 & 26,38 \\
\hline Anorexia & 11.8 & 17.8 & $0.80[0.63-1.00]$ & 0.05 & 20,26 \\
\hline Cough & 29.2 & 23.0 & $1.13[0.96-1.34]$ & 0.15 & 20,26 \\
\hline Diarrhoea & 6.0 & 8.6 & $1.28[0.96-1.73]$ & 0.11 & 20,26 \\
\hline Vomiting & 1.2 & 5.2 & $0.63[0.47-0.85]$ & *0.002 & $20,26,38$ \\
\hline SAE & 1.3 & 5.2 & $0.45[0.27-0.74]$ & ${ }^{*} 0.002$ & 26,38 \\
\hline \multicolumn{6}{|c|}{ Relative risk of $A E$ s between $A L$ and $A M$} \\
\hline Weakness & 64.9 & 58.2 & $1.12[1.04-1.21]$ & ${ }^{*} 0.004$ & 39,40 \\
\hline Abdominal pain & 1.7 & 3.8 & $0.44[0.14-1.41]$ & 0.17 & 39,40 \\
\hline Vomiting & 21.3 & 22.8 & $0.75[0.27-2.05]$ & 0.57 & 39,40 \\
\hline
\end{tabular}

₹ Random effect model.

* $(<0.05)$ statistically significant'.

\section{$A L$ and $A A Z$}

Only one RCT involving 261 patients compared the safety of AAZ with AL in paediatric patients [41]. This study showed that children taking AAZ have a significantly higher risk of vomiting than those on AL ( $p=$ 0.02). The risk of other AEs such as: dizziness, convulsion, respiratory and dermatological events were not significantly different in both treatment groups.

\section{Discussion}

This review identified cough as the most common adverse event in children receiving AL (Table 2). Other common adverse events are: abdominal pain, vomiting, anaemia, headache and diarrhoea. These findings have also been reported by other authors [9,42]. Many of the AEs were adjudged to be symptoms of malaria or signs of a progression of the disease. Generally, AL was well tolerated with only a few SAEs recorded. Only two unnamed SAEs were considered to be related to $\mathrm{AL}$ treatment. AL treated patients showed a significantly lower risk of vomiting compared with ASAQ, ACD and AAZ. A higher risk of weakness was observed in AL treated children compared with AM.

Due to increased risk of haemolysis, the clinical development of ACD, which is a very effective anti-malarial 
drug, was terminated at phase III [43]. A multicentre RCT by Premji et al. [38] has demonstrated a higher incidence of haemolysis in children receiving ACD than AL. Given the high prevalence of glucose 6-phosphate dehydrogenase (G6PD) deficiency (up to $30 \%$ ) in subSaharan Africa [44], and the fact that G6PD deficient children are prone to the haemolytic effect of the oxidant metabolite of dapsone [45], halting the development of ACD for malaria treatment in Africa was justified. Malderen et al. [46] showed that G6PD deficient children treated with ACD have a higher, but nonstatistically significant risk of having haemolysis and a $>2 \mathrm{~g} / \mathrm{dl}$ drop in their haematocrit, than non-deficient patients. Although ACD development has been stopped, it may still be relevant in the future fight against malaria. If such time ever comes, treatment would have to be individualized, with rapid test of G6PD status done before ACD prescription. Such tests have been approved by the US Food and Drug Administration for warfarin therapy and colon cancer treatment $[47,48]$.

Although mefloquine is associated with neuropsychiatric symptoms such as nightmares, hallucinations and anxiety [49-51], none was recorded in the two RCTs involving AM in this review. The small number of patients involved in both studies may not be adequately powered to detect this event. Gastrointestinal events were the most common adverse events in patients on AM. This is similar to the report from a study in Nigeria [52]. None of the gastrointestinal events however showed a significant difference between the patients on AM and AL. Treatment with $A L$, more than $A M$, significantly increased the risk of weakness of the body.

Some of the meta-analyses were limited by the relatively small number of patients in the comparator groups. Therefore, caution is required when extrapolating the results to the general population. Besides, such small sample size may not be sufficiently powered to detect rare events. Several of the RCTs reported adverse events rather than adverse reactions of the antimalarial drugs. This made it impossible to determine the causal relationship between the antimalarial drugs and the AEs. It was, therefore, difficult to determine whether an $\mathrm{AE}$ is symptomatic of the disease or drug related. In some other studies, safety reporting was either selective or inadequate, with some authors failing to indicate the severity of AEs. Some of these limitations have been identified in studies evaluating the quality of safety reporting in RCTs $[12,53]$.

\section{Conclusion}

Artemether-lumefantrine combination is as safe as ASAQ and DP for use in children. Common adverse events are cough and gastrointestinal symptoms. Haemolysis in G6PD deficient children makes the use of ACD undesirable. The few numbers of studies comparing $\mathrm{AL}$ with AM and AAZ would not enable us to make a firm conclusion on their comparative safety; therefore, more studies are needed to determine the comparative safety of AL with AM and AAZ.

\section{Abbreviations}

AAZ: Artesunate-azithromycin; ACD: Chorproguanil-dapsone-artesunate; ACT: Artemisinin combination therapy; AE: Adverse event; AL: Artemetherlumefantrine; AM: Artesunate-mefloquine; ASAQ: Artesunate-amodiaquine; Cl: Confidence interval; CONSORT: CONsolidated Standards of Reporting Trials; DP: Dihydroartemisinine-piperaquine; G6PD: Glucose-6-phosphate dehydrogenase; RCT: Randomized controlled trial; RR: Relative risk; SAE: Serious adverse event; WHO: World Health Organization.

\section{Competing interests}

The authors declare that they have no competing interests.

\section{Authors' contributions}

$\mathrm{OE}$ and KAO conceived the idea and planned the research; OE performed the database search; OE and KAO reviewed the retrieved papers for eligibility and performed the data extraction; OE and KAO performed the risk of bias assessment; OE performed the meta-analyses; OE wrote the first draft; KO edited and reviewed the manuscript; OE prepared the final draft. Both OE and $\mathrm{KAO}$ agreed to the final draft of the manuscript.

\section{Author details}

${ }^{1}$ Academic Division of Child Health, University of Nottingham, Derbyshire Children's Hospital, Derby DE22 3DT, UK. 'Department of Pharmacology, Lagos State University College of Medicine, IkejaLagos state, Nigeria.

Received: 10 July 2013 Accepted: 28 October 2013

Published: 1 November 2013

\section{References}

1. World Health Organization: Malaria. http://www.who.int/mediacentre/ factsheets/fs094/en/.

2. WHO: Antimalarial drug combination therapy: report of a technical consultation. Geneva: World Health Organization; 2001. http://whqlibdoc. who.int/hq/2001/WHO_CDS_RBM_2001.35.pdf.

3. Makanga M, Krudsood S: The clinical efficacy of artemether/lumefantrine (Coartem). Malar J 2009, 8(Suppl 1):S5.

4. Kokwaro G, Mwai L, Nzila A: Artemether/lumefantrine in the treatment of uncomplicated falciparum malaria. Expert Opin Pharmacother 2007, 8:75-94.

5. Ezzet F, Mull R, Karbwang J: Population pharmacokinetics and therapeutic response of CGP 56697(artemether + benflumetol) in malaria patients. Br J Clin Pharmacol 1998, 46:553-561.

6. Lefevre G, Thomsen MS: Clinical pharmacokinetics of artemether and lumefantrine (Riamet $^{\oplus}$ ). Clin Drug Investig 1999, 18:467-480.

7. Premji ZG: Coartem ${ }^{\oplus}$ : the journey to the clinic. Malar J 2009, 8:S3

8. Falade C, Manyando C: Safety profile of Coartem: the evidence base. Malar J 2009, 8:S6.

9. Artemether-lumefantrine full prescribing information. [http://www. pharma.us.novartis.com/cs/www.pharma.us.novartis.com/product/pi/pdf/ coartem.pdf]

10. Bakshi R, Hermeling-Fritz I, Gathmann I, Alteri E: An integrated assessment of the clinical safety of artemether-lumefantrine: a new oral fixed-dose combination antimalarial drug. Trans R Soc Trop Med Hyg 2000, 94:419-424.

11. Cochrane bias method group: Assessing risk of bias in included studies. http://bmg.cochrane.org/assessing-risk-bias-included-studies.

12. de Vries TW, van Roon EN: Low quality of reporting adverse drug reactions in paediatric randomised controlled trials. Arch Dis Child 2010, 95:1023-1026.

13. Viera AJ, Garrett JM: Understanding interobserver agreement: the kappa statistic. Fam Med 2005, 37:360-363.

14. DerSimonian R, Laird N: Meta-analysis in clinical trials. Contr Clin Trials 1986, 7:177-188

15. Arinaitwe E, Sandison TG, Wanzira H, Kakuru A, Homsy J, Kalamya J, Kamya MR, Vora N, Greenhouse B, Rosenthal PJ, Tappero J, Dorsey G: Artemether- 
lumefantrine versus dihydroartemisinin-piperaquine for falciparum malaria: a longitudinal, randomized trial in young Ugandan children. Clin Infect Dis 2009, 49:1629-1637.

16. Bassat $Q$, Mulenga $M$, Tinto H, Piola P, Borrmann S, Menéndez C, Nambozi M, Valéa I, Nabasumba C, Sasi P, Bacchieri A, Corsi M, Ubben D, Talisuna A, D'Alessandro U: Dihydroartemisinin-piperaquine and artemetherlumefantrine for treating uncomplicated malaria in African children: a randomised, non-inferiority trial. PLoS One 2009, 4:e7871.

17. Kamya MR, Yeka A, Bukirwa H, Lugemwa M, Rwakimari JB, Staedke SG, Talisuna AO, Greenhouse B, Nosten F, Rosenthal PJ, Wabwire-Mangen F, Dorsey G: Artemether-lumefantrine versus dihydroartemisininpiperaquine for treatment of malaria: a randomized trial. PLoS Clin Trials 2007, 2:e20.

18. Katrak S, Gasasira A, Arinaitwe E, Kakuru A, Wanzira H, Bigira V, Sandison TG, Homsy J, Tappero JW, Kamya MR, Dorsey G: Safety and tolerability of artemether-lumefantrine versus dihydroartemisinin-piperaquine for malaria in young HIV-infected and uninfected children. Malar J 2009, 8:272.

19. Yeka A, Dorsey G, Kamya MR, Talisuna A, Lugemwa M, Rwakimari JB, Staedke SG, Rosenthal PJ, Wabwire-Mangen F, Bukirwa H: Artemether-lumefantrine versus dihydroartemisinin-piperaquine for treating uncomplicated malaria: a randomized trial to guide policy in Uganda. PLoS One 2008, 3:e2390

20. Four Artemisinin-Based Combinations (4ABC) Study Group: A head-to-head comparison of four artemisinin-based combinations for treating uncomplicated malaria in African children: a randomized trial. PLoS Med 2011, 8:e1001119.

21. Zongo I, Dorsey G, Rouamba N, Dokomajilar C, Séré Y, Rosenthal PJ, Ouédraogo JB: Randomized comparison of amodiaquine plus sulfadoxine-pyrimethamine, artemether-lumefantrine, and dihydroartemisinin-piperaquine for the treatment of uncomplicated Plasmodium falciparum malaria in Burkina Faso. Clin Infect Dis 2007, 45:1453-1461.

22. Nambozi M, Van Geertruyden JP, Hachizovu S, Chaponda M, Mukwamataba D, Mulenga M, Ubben D, D'Alessandro U: Safety and efficacy of dihydroartemisinin-piperaquine versus artemether-lumefantrine in the treatment of uncomplicated Plasmodium falciparum malaria in Zambian children. Malar J 2011, 10:50.

23. Creek D, Bigira V, Arinaitwe E, Wanzira H, Kakuru A, Tappero J, Kamya MR, Dorsey G, Sandison TG: Increased risk of early vomiting among infants and young children treated with dihydroartemisinin-piperaquine compared with artemether-lumefantrine for uncomplicated malaria. Am J Trop Med Hyg 2010, 83:873-875.

24. Mens PF, Sawa P, van Amsterdam SM, Versteeg I, Omar SA, Schallig HD, Kager PA: A randomized trial to monitor the efficacy and effectiveness by QT-NASBA of artemether-lumefantrine versus dihydroartemisininpiperaquine for treatment and transmission control of uncomplicated Plasmodium falciparum malaria in western Kenya. Malar J 2008, 7:237.

25. Karunajeewa HA, Mueller I, Senn M, Lin E, Law I, Gomorrai PS, Oa O, Griffin S, Kotab K, Suano P, Tarongka N, Ura A, Lautu D, Page-Sharp M, Wong R, Salman S, Siba P, llett KF, Davis TM: A trial of combination antimalarial therapies in children from Papua New Guinea. N Engl J Med 2008, 359:2545-2557.

26. Owusu-Agyei $S$, Asante KP, Owusu R, Adjuik M, Amenga-Etego S, Dosoo DK, Gyapong J, Greenwood B, Chandramohan D: An open label, randomised trial of artesunate + amodiaquine, artesunate + chlorproguanil-dapsone and artemether-lumefantrine for the treatment of uncomplicated malaria. PLoS One 2008, 3:e2530.

27. Adjei GO, Kurtzhals JA, Rodrigues OP, Alifrangis M, Hoegberg LC, Kitcher ED, Badoe EV, Lamptey R, Goka BQ: Amodiaquine-artesunate vs artemetherlumefantrine for uncomplicated malaria in Ghanaian children: a randomized efficacy and safety trial with one year follow-up. Malar J 2008, 7:127.

28. Michael OS, Gbotosho GO, Folarin OA, Okuboyejo T, Sowunmi A, Oduola AM, Happi CT: Early variations in Plasmodium falciparum dynamics in Nigerian children after treatment with two artemisinin-based combinations: implications on delayed parasite clearance. Malar J 2010, 9:335.

29. Faucher JF, Aubouy A, Adeothy A, Cottrell G, Doritchamou J, Gourmel B, Houzé P, Kossou H, Amedome H, Massougbodji A, Cot M, Deloron P: Comparison of sulfadoxine-pyrimethamine, unsupervised artemetherlumefantrine, and unsupervised artesunate-amodiaquine fixed-dose formulation for uncomplicated Plasmodium falciparum malaria in Benin: a randomized effectiveness noninferiority trial. J Infect Dis 2009, 200:57-65.
30. Kobbe R, Klein P, Adjei S, Amemasor S, Thompson WN, Heidemann $H$, Nielsen MV, Vohwinkel J, Hogan B, Kreuels B, Bührlen M, Loag W, Ansong D, May J: A randomized trial on effectiveness of artemether-lumefantrine versus artesunate plus amodiaquine for unsupervised treatment of uncomplicated Plasmodium falciparum malaria in Ghanaian children. Malar J 2008, 7:261.

31. Maiteki-Sebuguzi $C$, Jagannathan P, Yau VM, Clark TD, Njama-Meya D, Nzarubara B, Talisuna AO, Kamya MR, Rosenthal PJ, Dorsey G, Staedke SG: Safety and tolerability of combination antimalarial therapies for uncomplicated falciparum malaria in Ugandan children. Malar J 2008, 7:106.

32. Bukirwa H, Yeka A, Kamya MR, Talisuna A, Banek K, Bakyaita N, Rwakimari JB, Rosenthal PJ, Wabwire-Mangen F, Dorsey G, Staedke SG: Artemisinin combination therapies for treatment of uncomplicated malaria in Uganda. PLoS Clin Trials 2006, 1:e7.

33. Falade CO, Ogundele AO, Yusuf BO, Ademowo OG, Ladipo SM: High efficacy of two artemisinin-based combinations (artemether-lumefantrine and artesunate plus amodiaquine) for acute uncomplicated malaria in Ibadan, Nigeria. Trop Med Int Health 2008, 13:635-643.

34. Gbotosho GO, Sowunmi A, Okuboyejo TM, Happi CT, Folarin OA, Michae OS, Adewoye EO: Therapeutic efficacy and effects of artemetherlumefantrine and artesunate-amodiaquine coformulated or copackaged on malaria-associated anemia in children with uncomplicated Plasmodium falciparum malaria in Southwest Nigeria. Am J Trop Med Hyg 2011, 84:813-819.

35. Mutabingwa TK, Anthony D, Heller A, Hallett R, Ahmed J, Drakeley C, Greenwood BM, Whitty CJ: Amodiaquine alone, amodiaquine + sulfadoxine-pyrimethamine, amodiaquine + artesunate, and artemetherlumefantrine for outpatient treatment of malaria in Tanzanian children: a four-arm randomised effectiveness trial. Lancet 2005, 365:1474-1480

36. Mårtensson A, Strömberg J, Sisowath C, Msellem MI, Gil JP, Montgomery SM, Olliaro P, Ali AS, Björkman A: Efficacy of artesunate plus amodiaquine versus that of artemether-lumefantrine for the treatment of uncomplicated childhood Plasmodium falciparum malaria in Zanzibar, Tanzania. Clin Infect Dis 2005, 41:1079-1106.

37. Meremikwu M, Alaribe A, Ejemot R, Oyo-Ita A, Ekenjoku J, Nwachukwu C, Ordu D, Ezedinachi E: Artemether-lumefantrine versus artesunate plus amodiaquine for treating uncomplicated childhood malaria in Nigeria: randomized controlled trial. Malar J 2006, 5:43.

38. Premii Z, Umeh RE, Owusu-Agyei S, Esamai F, Ezedinachi EU, Oguche S, Borrmann S, Sowunmi A, Duparc S, Kirby PL, Pamba A, Kellam L, Guiguemdé R, Greenwood B, Ward SA, Winstanley PA: Chlorproguanil-dapsone-artesunate versus artemether-lumefantrine: a randomized, double-blind phase III trial in African children and adolescents with uncomplicated Plasmodium falciparum malaria. PLoS One 2009, 4:e6682.

39. Toure OA, Kouame MG, Didier YJ, Berenger AA, Djerea K, Genevieve GO, Penali LK: Artesunate/mefloquine paediatric formulation vs. artemether/ lumefantrine for the treatment of uncomplicated Plasmodium falciparum in Anonkoua kouté, Côte d'Ivoire. Trop Med Int Health 2011, 16:290-297.

40. Faye B, Ndiaye UL, Tine R, Sylla K, Gueye A, Lô AC, Gaye O: A randomized trial of artesunate mefloquine versus artemether lumefantrine for the treatment of uncomplicated Plasmodium falciparum malaria in Senegalese children. Am J Trop Med Hyg 2010, 82:140-144.

41. Sykes A, Hendriksen I, Mtove G, Mandea V, Mrema H, Rutta B, Mapunda E, Manjurano A, Amos B, Reyburn H, Whitty CJ: Azithromycin plus artesunate versus artemether-lumefantrine for treatment of uncomplicated malaria in Tanzanian children: a randomized, controlled trial. Clin Infect Dis 2009, 49:1195-1201.

42. Makanga M, Premji Z, Falade C, Karbwang J, Mueller EA, Andriano K, Hunt P, De Palacios Pl: Efficacy and safety of the six-dose regimen of artemetherlumefantrine in pediatrics with uncomplicated Plasmodium falciparum malaria: a pooled analysis of individual patient data. Am J Trop Med Hyg 2006, 74:991-998.

43. Update on GSK's malaria treatments: Dacart and Lapdap. http://www.gsk. com/media/press-releases/2008/update-on-gsks-malaria-treatments-dacartand-lapdap.html.

44. Howes RE, Piel FB, Patil AP, Nyangiri OA, Gething PW, Dewi M, Hogg MM, Battle KE, Padilla CD, Baird JK, Hay SI: G6PD deficiency prevalence and estimates of affected populations in malaria endemic countries: a geostatistical model-based map. PLoS Med 2012, 9:e1001339.

45. Carrazza MZ, Carrazza FR, Oga S: Clinical and laboratory parameters in dapsone acute intoxication. Rev Saude Publica 2000, 34:396-401. 
46. Van Malderen C, Van Geertruyden JP, Machevo S, González R, Bassat Q, Talisuna A, Yeka A, Nabasumba C, Piola P, Daniel A, Turyakira E, Forret P, Van Overmeir C, van Loen H, Robert A, D' Alessandro U: Glucose-6-phosphate dehydrogenase deficiency, chlorproguanil-dapsone with artesunate and post-treatment haemolysis in African children treated for uncomplicated malaria. Malar J 2012, 11:139.

47. FDA clears genetic lab test for warfarin Sensitivity. www.fda.gov/newsevents/ newsroom/pressannouncements/2007/ucm 108984.htm.

48. FDA approves Erbitux for colorectal cancer. http://www.fda.gov/NewsEvents/ Newsroom/PressAnnouncements/2004/ucm108244.htm.

49. Mayxay M, Khanthavong M, Lindegårdh N, Keola S, Barends M, Pongvongsa T, Yapom R, Annerberg A, Phompida S, Phetsouvanh R, White NJ, Newton PN: Randomized comparison of chloroquine plus sulfadoxinepyrimethamine versus artesunate plus mefloquine versus artemetherlumefantrine in the treatment of uncomplicated falciparum malaria in the Lao People's Democratic Republic. Clin Infect Dis 2004, 39:1139-1147.

50. Schlagenhauf P, Adamcova M, Regep L, Schaerer MT, Bansod S, Rhein HG: Use of mefloquine in children - a review of dosage, pharmacokinetics and tolerability data. Malar J 2011, 10:292.

51. Lariam (mefloquine hydrochloride) $250 \mathrm{mg}$ tablets: Detailed View: Safety Labeling Changes Approved By FDA Center for Drug Evaluation and Research (CDER). 2009. http://www.fda.gov/Safety/MedWatch/Safetylnformation/ ucm181182.htm

52. Agomo PU, Meremikwu MM, Watila IM, Omalu IJ, Odey FA, Oguche S, Ezeiru VI, Aina OO: Efficacy, safety and tolerability of artesunatemefloquine in the treatment of uncomplicated Plasmodium falciparum malaria in four geographic zones of Nigeria. Malar J 2008, 7:172.

53. Anderson M, Choonara I: A systematic review of safety monitoring and drug toxicity in published randomized controlled trials of antiepileptic drugs in children over a 10-year period. Arch Dis Child 2011, 95:731-738.

doi:10.1186/1475-2875-12-385

Cite this article as: Egunsola and Oshikoya: Comparative safety of artemether-lumefantrine and other artemisinin-based combinations in children: a systematic review. Malaria Journal 2013 12:385.

\section{Submit your next manuscript to BioMed Central and take full advantage of:}

- Convenient online submission

- Thorough peer review

- No space constraints or color figure charges

- Immediate publication on acceptance

- Inclusion in PubMed, CAS, Scopus and Google Scholar

- Research which is freely available for redistribution 